\title{
Taking Indigenous Technology seriously: The Case of Inter-cropping Techniques in East Africa
}

\section{Deryke Belshaw}

\section{Introduction}

Inter-cropping or associated cropping is an indigenous technique of crop production which is widely practised in small-scale farm systems in the tropics. Some of the complementary interactions between plants grown in mixed stands have long been recognised in the scientific agricultural literature, especially those contributing to higher productivity per unit of land. The principle of mixed stand cropping is widely practised in modern research-derived agriculture in the sphere of sown pastures, such as clover-grass or lucernegrass mixtures.

When it comes to crop planting techniques, however, the orthodox approach in modern agricultural practice is to plant crops in pure stands, thereby restricting inter-crop complementarities to sequential effects within a rotation. This technique has formed the basis of virtually all agronomic research in tropical agriculture and also of the research-derived crop production practices which are promulgated for adoption on small farms through the agricultural extension services. The reasons for the dominance of the pure stand technique appear to be as follows:

-Pure stands combined with row planting are advantageous for (a) accurate control of the plant population and (b) the mechanisation of weeding and harvesting operations;

-Effective and profitable fertiliser and pest and disease control treatments are easier to calculate and apply when crops are grown in pure stands;

-Agricultural development policy has often focused on increasing the output of one crop, for example an export crop to earn foreign exchange and to generate government revenue, or a staple food crop for consumption in urban areas. Research and extension advice has concentrated, therefore, on ways of achieving increased output for a single crop rather than for the farm system as a whole;

-Techniques of production developed in plantation agriculture, which typically consists of cash crop monoculture, have been regarded as appropriate for adoption in small-scale agriculture;

- In general, agronomic research is considerably easier and generates results more quickly with pure stand rather than mixed stand cropping;

- The assumption is widespread that techniques which are appropriate for mechanised and capital-intensive arable farm systems in developed countries provide a model for the improvement of low productivity farming systems in the tropics; therefore, pure stand cropping, as an inherent feature of such 'modern' farm systems, is believed to be inherently superior to indigenous inter-cropping techniques.

This note focuses on changes in the attitudes of research workers to inter-cropping techniques in tropical Africa, and especially in the three East African countries, over the last twenty years.

Experimental research and farm surveys relating to inter-cropping in East Africa

An historical outline of applied scientific and economic research on inter-cropping systems in East Africa may be briefly presented as follows:

-Pioneer experiments were carried out in Tanganyika in the 1930s on techniques of intercropping the major peasant farm cash crop, cotton, with rice, maize or legumes (Wakefield, 1931; Robertson, 1941). An isolated experiment on cotton interplanted with groundnuts was also reported from northern Uganda in the same period (Hayes, 1937).

-A small amount of research on inter-cropping systems involving maize, castor and cotton as the major policy-relevant crops and sorghum, groundnuts and soya beans as complementary crops was carried out in Tanganyika in the period immediately before and after the attainment of Independence in 1961 (Evans, 1960; Evans and Sreedharan, 1962; Grimes, 1963).

- The possible technical and financial advantages of inter-cropping for small family farms, embodied in a critique of agronomic experimental procedures, were reviewed in a paper 
presented to East African meetings of agricultural economists/planners and of agricultural botanists, agronomists and plant breeders in $1965^{1}$ (Belshaw and Hall, published in German, 1966, and in English with minor additions, 1972). This material was included in agricultural economics courses given to all students in the Faculty of Agriculture at Makerere (which was training graduates for the three East African countries) during the period 1965-70.

-Agronomic research on the inter-cropping of maize and beans started at the same Faculty in 1970 in the context of an ODM-funded grain legume research project (Leakey, 1971).

-The possible merits of inter-cropping techniques were summarised in a paper reviewing aspects of crop production research, mainly in the tropics, which was widely distributed amongst East African agricultural research institutions (Leakey, 1970). ${ }^{2}$

- Research on inter-cropping began to proliferate in East Africa, starting with work at Mlingano and Ilonga research stations in Tanzania in 1969-70. ${ }^{3}$ This phase culminated in a conference held at the Faculty of Agriculture of the University of Dar es Salaam in 1976 when 31 papers on inter-cropping research were read. The majority of the 42 authors were drawn from the three East African countries, although work in Mauritius, Ethiopia and West Africa was also represented.

- Nevertheless, by early 1978 no recommended crop production practices involving intercropping techniques had been issued to agricultural extension services and farmers in East Africa. ${ }^{4}$ This may reflect the fact that the reported research has been concentrated in university and international research stations rather than in government stations.

\footnotetext{
I The economists' meeting was the workshop/conference which set up, in the following year, the East African Agricultural Economics Society, and the botanists' meeting was of a specialist committee of the East African Agriculture and Forestry Research Organisation. The paper referred to was accorded a distinctly hostile reception at the latter meeting.

2 C. L. A. Leakey's interest in inter-cropping had been stimulated by re-reading a chapter of a book written by his father-L. S. B. Leakey -in the 1930s which had favourably assessed this practice in Kikuyu agriculture (L. S. B. Leakey 1937: Chap. 8)

3 Private communication from Dr. D. P. Gibbon, Overseas Development Group and ICARDA, 1978

4 A policy recommendation to carry out field trials on intercropping techniques for maize production had been made by the UNDP/FAO regional planning team working in Iringa Region, Tanzania (UNDP/FAO 1976). Implementation of the follow-up project (FAO 1975) by an EEC-funded team of consultants began in September 1977.
}

\section{Problems with agronomic research on inter- cropping techniques}

The possible advantages of inter-cropping in any particular circumstance have been summarised elsewhere as follows:

(i) The different rooting systems exhibited by various plants ensure that they are not competing for plant nutrients and soil moisture in the same zone but are exploiting different levels of the soil profile.

(ii) Often one crop will provide a favourable micro-climate for another, e.g. bananas providing shade for young coffee bushes.

(iii) There is the possibility of a complementary effect when nitrogen-fixing plants are grown with non-nitrogen-fixing plants.

(iv) A scatter of seed among another species of ten means that the minority plants can grow free from the diseases and pests which might ruin them in pure stand. An example of this is the growing of gourds which are scattered through the fields so that a proportion escape the attacks of the melon fly.

(v) Mixed cropping can lead to lower labour requirements by bringing about a quick vegetation cover which will smother weeds. This is especially the case in crops which are commonly grown in rows, e.g. cotton, coffee, tea and cassava, since they all take time to establish and leave a large area of soil unprotected against weed encroachment and soil erosion. By growing a shallow rooting short-term crop, such as beans, the farmer may minimize weed infestation and so reduce labour inputs.

(vi) Protection of the soil and water resources under the plant cover.

(vii) R. C. Grimes concluded from a series of experiments that alternate row cropping gave a greater total return than growing cotton and maize in pure stands; it can be calculated that the price of maize would have to fall below $10 \mathrm{cts} / \mathrm{lb}$. to invalidate his conclusion. In areas where land is a limiting factor this type of mixed cropping is especially important as it enables the farmer to grow a series of crops over the year. For example, cotton can be planted in the groundnut crop or between the rows of an almost mature tobacco stand. The first crop is then harvested and the rows of cotton come away often with a new crop of beans between them. A strict adherence to 
pure stands would lose the farmer two additional crops in the above circumstances. Thus, mixed cropping can be beneficial where land is limiting by allowing more crops, and where labour is limiting by reducing work required for weeding and by spreading the benefits from the work involved in clearing new land from bush.

(viii) In a farm management study in Bukedi District of Uganda (Othieno and Belshaw, 1965), farmers gave as an additional reason the fact that mixing of food crops provided a wider variety of foods over an extended harvesting period, successive sowing of crop mixtures facilitating this.

(ix) The risk factor was also an important consideration which led to mixed cropping. Farmers pointed out that a crop in one stand might fail to germinate or get damaged by bad weather whereas in a mixture there was a good chance that part of the crop would survive'. 5

It can be seen that these possible advantages assist one or other of five objective functions which may be pursued by farm families. These are:

-Raising total farm output;

-Reducing variance in output levels;

-Reducing labour inputs per unit of product;

-Assisting in ensuring a conveniently placed and timely supply of a varied range of fresh foods;

-Avoiding or reducing cash outlays on farm inputs such as fertiliser.

It is notable, however, that the recent experimental research continues to apply the standard agronomic criterion of yield per unit area to evaluate the appropriateness of the inter-cropping techniques. This criterion is only a partial indicator of the first objective function noted above. The utility of inter-cropping in meeting the other farm objectives is typically ignored in monodisciplinary agronomic and plant breeding research. However, where a farm economics analysis has been used within a multi-disciplinary approach, major emphasis is typically placed on measuring risk factors (the second objective func-

\footnotetext{
5 The preceding summary is taken from Belshaw and Hall
} 1072 tion above; e.g. Francis and Sanders, 1977). In any event, it seems more probable that the operative set of objective functions and the associated selection criteria will be identified if the formal research phase is preceded by a field survey of farmers' actual production techniques and their stated reasons or inferred rationales for utilising them.

\section{Procedures for participatory research on appro- priate production techniques}

A sequence of research activities designed to overcome the problem noted in the previous section has been proposed by Bartlett and others (1976). This consists of six steps:

1 A farm survey is mounted to identify the field cropping practices in use.

2 Scientists present their views on possible changes in production practices.

3 An economist makes an assessment of probable costs to the farmer of these changes.

4 Scientists assess probable yield increases available from improved methods and select the avenues of research to be emphasised.

5 Experimental work to find optimal levels of use of a practice is conducted under controlled conditions similar to those used by farmers.

6 Experimental work is accompanied and followed by farmers' tests of the innovation(s).

Local community participation occurs in stages (1) and (6), and also, of course, in the final decision whether to adopt the recommended practice. It may be desirable that further community pressure is brought to bear on the formal research institutions through high-level political leadership, in order to ensure a commitment to this type of approach. In the particular case of inter-cropping, formal research which builds upon the basis of indigenous knowledge and practice would appear to be preferable to the attempted direct transfer of an existing indigenous practice to a new area without prior analysis, testing, and the possible incorporation of improved components such as fertiliser or new varieties.

At the core of such an approach is the concept of multi-disciplinary research on farmer systems (Rimenyi 1977: 3; see also Norman 1976: 13-14). This approach takes the fundamental human 
needs of rural farmers and their dependents - the family and, if appropriate, farm workers, as well as the interests of future generations-as the central concern of the research activity. The material components of the farming systemenergy flows, plants, animals, technology or whatever-enter only as secondary considerations, as constraints or potentials, in the search for better alternatives for improving human welfare.

\section{References}

Bartlett, C. D. S, E. A. Manday and G. I. Mlay, 'Assessment of Innovations in Inter-cropping Systems', Paper for Symposium on Inter-cropping in Semi-arid Areas, Morogoro, Tanzania, 1976

Belshaw, D. G. R. and M. Hall, 'Die praktische Nutzanwendung Landwirtschaftlicher Versuchsergebnsse', Zeit. für auslandische Landwirtschaft, 4, 1966

Belshaw, D. G. R. and M. Hall, 'The Analysis and Use of Agricultural Experimental Data in Tropical Africa', East African Journal of Rural Development, 5, 1972

Evans, A. C., 'Studies of Inter-cropping I: Maize or Sorghum with Groundnuts', East African Agricultural and Forestry Journal, 26, 1960

Evans, A. C. and A. Sreedharan, 'Studies of Inter-cropping II: Castor Bean with Groundnut or Soya Bean', East African Agricultural and Forestry Journal, 28, 1962

FAO, 'Integrated Rural Development Project, Iringa Region', FAO, Dar es Salaam 1975 (mimeo)

Francis, C. A. and J. H. Sanders, 'Economic Analysis of Bean and Maize Systems: Monoculture versus Associated Cropping', C.I.A.T., Colombia, 1977 (mimeo)

Grimes, R. C., 'Inter-cropping and Alternative Row Cropping of Cotton and Maize', East
African Agricultural and Forestry Journal, 28, 1963

Hayes, T. R., Some Aspects of Groundnut Production, East African Agricultural Journal, 2, 1937

Leakey, C. L. A., 'Heterogeneous Agricultural Populations', Agricultural Progress, 45, 1970

Leakey, C. L. A., Factors affecting increased Production and Marketing of Food Crops in Uganda, East African Journal of Rural Development, 4, 1971

Leakey, L. S. B., Kenya: Contrasts and Problems, Macmillan, London, 1934

Norman, D. W., 'Developing Mixed Cropping Systems Relevant to the Farmers' Environment', Paper for Symposium on Inter-cropping in Semi-arid Areas, Morogoro, Tanzania, 1976

Othieno, T. M. and D. G. R. Belshaw, 'Systems of African Peasant Farming in Bukedi District, Uganda', East African Institute of Social Research Conference Paper, 1965, reprinted in Jon Moris and Gerald Saylor (eds), Technical Innovation and Farm Development in East Africa, Makerere Unversity, Kampala, Uganda, 1974

Rimenyi, J. V., 'Issues in Farming Systems Research: A Report on a Ford Foundation Seminar', Ford Foundation, New York, 1977 (mimeo)

Robertson, J. K., 'Mixed or Multiple Cropping in Native Agricultural Practice', East African Agricultural Journal, 6, 1941

UNDP/FAO, Iringa Region, Tanzania: Integrated Rural Development Proposals for the Third Five-year Plan, 1976-81, 2 vols, Overseas Development Group, University of East Anglia, Norwich, 1976

Wakefield, A. J., Cotton Experiments in Tanganyika Territory under Riverain Conditions, Empire Cotton Growing Review, 8, 1931 